\title{
Identification of native and invasive subspecies of common reed (Phragmites australis) in Alberta, Canada by RNase H- dependent PCR
}

\begin{tabular}{|c|c|}
\hline Journal: & Botany \\
\hline Manuscript ID & cjb-2017-0152.R1 \\
\hline Manuscript Type: & Note \\
\hline Date Submitted by the Author: & $12-$ Oct-2017 \\
\hline Complete List of Authors: & $\begin{array}{l}\text { Zuzak, Krista; Crop Diversification Centre North, Alberta Agriculture and } \\
\text { Forestry, Edmonton, Alberta, T5Y 6H3, Canada } \\
\text { Yang, Yalong; Crop Diversification Centre North, Alberta Agriculture and } \\
\text { Forestry, Edmonton, Alberta, T5Y 6H3, Canada } \\
\text { Kimmel, Nicole; Crop Diversification Centre North, Alberta Agriculture and } \\
\text { Forestry, Edmonton, Alberta, T5Y 6H3, Canada } \\
\text { Harding, Michael; Crop Diversification Centre South, Alberta Agriculture } \\
\text { and Forestry, Brooks, Alberta, T1R 1E6, Canada } \\
\text { Feindel, David; Crop Diversification Centre North, Alberta Agriculture and } \\
\text { Forestry, Edmonton, Alberta, T5Y } 6 \mathrm{H} 3 \text {, Canada } \\
\text { Feng, Jie; Crop Diversification Centre North, Alberta Agriculture and } \\
\text { Forestry, Edmonton, Alberta, T5Y } 6 \mathrm{H} 3 \text {, Canada }\end{array}$ \\
\hline $\begin{array}{r}\text { Is the invited manuscript for } \\
\text { consideration in a Special } \\
\text { Issue? : }\end{array}$ & N/A \\
\hline Keyword: & rhPCR, RFLP, haplotypes, DNA polymorphism, RNase H-dependent \\
\hline
\end{tabular}

\section{SCHOLARONEm \\ Manuscripts}


Identification of native and invasive subspecies of common reed (Phragmites australis) in Alberta, Canada by RNase H-dependent PCR

Krista Zuzak ${ }^{1}$, Yalong Yang ${ }^{1}$, Nicole Kimmel ${ }^{1}$, Michael Harding ${ }^{2}$, David Feindel ${ }^{1}$, and Jie Feng $^{1}$

${ }^{1}$ Crop Diversification Centre North, Alberta Agriculture and Forestry, Edmonton, Alberta, T5Y

6H3, Canada

${ }^{2}$ Crop Diversification Centre South, Alberta Agriculture and Forestry, Brooks, Alberta, T1R 1E6, Canada

Corresponding author: Jie Feng (email: jie.feng@gov.ab.ca) 


\begin{abstract}
Colonies of the invasive subspecies of common reed (Phragmites australis) were found in Alberta in 2016. To facilitate rapid subspecies identification necessary to support management of the invasive subspecies, a simple and time saving protocol was developed to differentiate the invasive from the native subspecies. This protocol was based on the RNase H-dependent PCR (rhPCR) technique, which utilizes the DNA polymorphism found in two chloroplast DNA regions. Compared to the widely used restriction fragment length polymorphism (RFLP) protocol, the rhPCR had the same level of accuracy on subspecies identification but is simpler and less time consuming. Using both the rhPCR and RFLP techniques, twenty-seven P. australis samples derived from 21 colonies in nine Alberta counties were tested to determine their subspecies identity. Fourteen colonies were identified as invasive subspecies and seven were native subspecies. Based on these preliminary data, we concluded that the invasive subspecies has established across Alberta and now may be more common than the native subspecies. In addition, RFLP results confirmed that the rhPCR was accurate and could be used independently to identify $P$. australis subspecies in future studies.
\end{abstract}

\title{
Key words:
}

rhPCR, RFLP, haplotypes, DNA polymorphism, RNase H-dependent 


\section{Introduction}

Phragmites australis (Cav.) Trin. ex Steud is an emergent aquatic species with a perennial growth habit (Mal and Narine 2004). A native subspecies, P. australis subsp. americanus Saltonstall, P.M. Peterson, and Soreng, was historically present in wetlands across North American (Orson 1999). Over the past 150 years however, the introduction of the nonnative European subspecies, P. australis (Cav.) Trin. ex Steud. subsp. australis, has resulted in population increases and range expansion (Saltonstall 2002). This introduction has dramatically altered estuarine and freshwater communities (Chambers et al. 1999) and caused reductions in the distribution of the native subspecies due to competitive exclusion, i.e. formation of monocultures as it establishes (Saltonstall 2002; Saltonstall et al. 2010).

The native subspecies has been reported in most Canadian provinces and territories (Mal and Narine 2004). The first record of the introduced invasive subspecies in Canada was in 1910 in Nova Scotia, and by the 1920s it had reached the St. Lawrence River, near Quebec City (Catling and Mitrow 2011). Since then it has been spreading westward and was expected to become established across most of southern Canada (Catling and Mitrow 2011). In Alberta, the invasive subspecies was found in two locations near Brooks in March of 2016 and seven other locations in 2017 (N. Kimmel, unpublished data) prior to the present study.

The native and the invasive subspecies have slight morphological differences, but overlap to some degree, making it difficult to identify subspecies identity in the field, especially if they are not in flower (Saltonstall et al. 2004). Saltonstall $(2002,2003 a)$ identified two regions of the chloroplast DNA that carry polymorphisms among P. australis populations. Based on the sequences of these two regions, stands of either native or invasive subspecies could be grouped into different haplotypes (Saltonstall 2002; Allen et al. 2017). There are mutations on these two 
DNA regions which are shared by all haplotypes of the invasive subspecies but not by those of the native subspecies. By utilizing these sequence mutations, Saltonstall (2003a) developed a restriction fragment length polymorphism (RFLP) technique to differentiate the two subspecies. The RFLP technique, as well as its derivative in which the PCR products were sequenced rather than digested, allow for consistent, accurate subspecies identification, but they also have the disadvantage of being time consuming. For example, two sequential PCR reactions are conducted and the resultant amplicons must be purified and analyzed. Analyses may be done by sequencing or restriction enzyme digestion and then sequence analysis or electrophoresis. To remedy this disadvantage, a simple and less time consuming technique, RNase H-dependent PCR (rhPCR), was employed and its efficiency and accuracy for subspecies identification was assessed.

The rhPCR technique relies on primers designed specific to the DNA sequences carrying the single nucleotide polymorphism between individuals (Dobosy et al. 2011). On the primer sequence, a ribonucleotide residue is used at the polymorphic site and is located several base pairs (bp) upstream of the 3' end of the primer. The primer is blocked at the 3' end by C3 spacers so the polymerase cannot start the amplification. The primer can be unblocked via hybridization to the template DNA sequence and subsequent cleavage at the 5' site of the ribonucleotide by the RNase H2 enzyme. The cleavage can only be effectively carried out when the ribonucleotide on the primer matches the nucleotide on the template; mismatch between the ribonucleotide and nucleotide results in little or no cleavage and as a consequence, the primer remains blocked. This technique can differentiate two individuals that carry a single nucleotide polymorphism within a DNA region through selective amplification of the DNA region from one but not the other. Furthermore, because the primers must hybridize to the target sequence on the template before 
they are cleaved, they are unable to form primer dimers. When applied to the detection of singlenucleotide polymorphisms, rhPCR was found to be far more sensitive than standard allelespecific PCR (Dobosy et al. 2011).

In this study, rhPCR primers were designed according to the sequence polymorphism on the two chloroplast DNA regions investigated by Saltonstall (2003a). Using these primers, rhPCR was performed in parallel with, and compared to, RFLP analysis on Alberta's P. australis samples. The objectives of this study were to 1) develop a new method for P. australis subspecies identification and 2) investigate the distribution of native and invasive $P$. australis in Alberta, Canada.

\section{Materials and Methods}

\section{Sample collection}

Phragmites australis samples were collected by Alberta Agricultural Fieldmen from nine counties and sent to the Alberta Plant Health Lab (APHL) at the Crop Diversification Centre North in Edmonton, Alberta. All samples were subject to DNA extraction immediately. A portion of each sample was kept at $-20^{\circ} \mathrm{C}$ for future use.

\section{General molecular techniques}

Genomic DNA was extracted from leaf or stem fragments using the DNeasy Plant Mini kit (Qiagen Canada, Toronto, ON). PCR primers were synthesized by Integrated DNA Technologies (Coralville, IA). All PCR, including those for RFLP and the rhPCR, were conducted in Promega PCR master mix (Promega, Madison, WI) using a Bio-Rad T100 thermal cycler (Bio-Rad Canada, Mississauga, $\mathrm{ON})$ with 35 cycles of denaturation at $94^{\circ} \mathrm{C}$ for $30 \sec (3 \mathrm{~min}$ for the first cycle), annealing at $52^{\circ} \mathrm{C}(\mathrm{RFLP})$ or $58^{\circ} \mathrm{C}$ (rhPCR) for $30 \mathrm{sec}$ and extension at $72^{\circ} \mathrm{C}$ for $45 \mathrm{sec}$, 
and a final extension at $72^{\circ} \mathrm{C}$ for $5 \mathrm{~min}$. Purification of PCR product was performed using the Wizard SV Gel and PCR Cleanup System (Promega). Electrophoresis was performed on 1\% agarose gels with GelGreen (VWR Canada, Mississauga, ON) staining. DNA bands were visualized using a GelDoc EZ Imaging System (Bio-Rad Canada).

\section{Restriction fragment length polymorphism (RFLP)}

The RFLP analysis followed the protocol of Larson et al. (2011), which was modified from Saltonstall (2003a). For each sample, two PCR reactions were conducted using the primer pairs $\operatorname{trn} \mathrm{LbR} / \operatorname{trn} \mathrm{L}$ and $r b c \mathrm{~L} / r b c \mathrm{~L} 3 \mathrm{R}$, respectively (Fig. 1 and Table 1). The volume was $30 \mu \mathrm{L}$ for each reaction, containing $0.25 \mu \mathrm{M}$ of each primer and $50 \mathrm{ng}$ template DNA. The PCR product was purified and eluted in $50 \mu \mathrm{L}$ water. Fifteen $\mu \mathrm{L}$ of each purified PCR product was digested respectively with 10 units of the restriction enzyme RsaI and HhaI (New England Biolabs, Ipswich, MA) in a $20-\mu \mathrm{L}$ reaction at $37^{\circ} \mathrm{C}$ for 2 hours. The digest as well as $10 \mu \mathrm{L}$ undigested PCR product were analyzed by electrophoresis.

\section{RNase H-dependent PCR (rhPCR)}

The whole genome sequences of the chloroplast from an invasive plant (Accession numbers KF730315) and a native plant (KJ825856) were retrieved from GenBank by searching the National Center for Biotechnology Information (NCBI) nucleotide database with the term "Phragmites australis chloroplast". The sequences of the four primers (Table 1) used in the RFLP analysis by Larson et al. (2011) were manually matched to the two genomic sequences. This procedure identified two chloroplast DNA regions on each chloroplast genome sequence: a portion of the intergenic spacer between the $\operatorname{trnT}$ (UGU) and $\operatorname{trnL}$ (UAA) and a portion of the intergenic spacer between the $r b c \mathrm{~L}$ and psal (Larson et al. 2011). For each of the two DNA regions, the two DNA sequences from the two subspecies were aligned using the NCBI Blast 
"Align two or more sequences" function (Fig. 1). Based on the aligned sequences, RNase Hdependent PCR primers were manually designed according to Dobosy et al. (2011) and the rhPCR guide (Integrated DNA Technologies 2017). rhPCR was conducted on each sample in $20-\mu \mathrm{L}$ reaction containing $1 \mathrm{mU}$ RNase H2 (Integrated DNA Technologies) for each primer pair, $0.25 \mu \mathrm{M}$ of each primer and $50 \mathrm{ng}$ template DNA.

\section{Sample analyses}

Initially five plant samples from five different counties were analyzed by RFLP. Based on the result of RFLP, one native and one invasive sample were chosen to test the efficiency and accuracy of rhPCR. Two rhPCR strategies were applied: 1) single rhPCR in which primer pairs trnL-F/trnL-R and rbcL-F/rbcL-R were used in alternative reactions and 2) duplex rhPCR in which the two primer pairs were used in one reaction. To evaluate the effect(s) of RNase H2 concentration on the rhPCR efficiency, the two plant samples were also tested by the two rhPCR strategies without RNase $\mathrm{H} 2$ and with $2 \mathrm{mU}$ RNase $\mathrm{H} 2$ per primer pair in $20-\mu \mathrm{L}$ reactions. Finally, all collected samples were analyzed by the RFLP and the duplex rhPCR with $1 \mathrm{mU}$ RNase $\mathrm{H} 2$ per primer pair (i.e. $2 \mathrm{mU}$ in each duplex reaction) in $20-\mu \mathrm{L}$ reactions.

\section{Results}

\section{Efficiency of the rhPCR on identification of $P$. australis subspecies}

Both RFLP and rhPCR would produce different bands from either the native or the invasive subspecies (Fig. 2A). The five selected $P$. australis samples were identified to the subspecies level by the RFLP analysis (Fig. 2B). When the trnT-trnL fragment was digested with RsaI, one fragment at $350 \mathrm{bp}$ could be visualized from samples 1,2,3 and 5, indicating that these samples were the invasive subspecies. Two fragments at 300 and $60 \mathrm{bp}$ were visualized from sample 4, 
indicating this sample was the native subspecies. When the $r b c \mathrm{~L}-p s a l$ fragment was digested with $H$ haI, two fragments at 200 and $100 \mathrm{bp}$ were visualized from the samples 1, 2, 3 and 5 and one fragment at $320 \mathrm{bp}$ was visualized from sample 4, confirming that samples 1, 2, 3 and 5 were invasive and sample 4 was the native subspecies. The efficiency of rhPCR on subspecies identification was tested on samples 3 and 4 (Fig. 2C). In the single rhPCR, a band at 230 bp was amplified by the primer pair rbcL-F/rbcL-R from sample 3 and a band at $330 \mathrm{bp}$ was amplified by the primer pair trnL-F/trnL-R from sample 4 . In the duplex rhPCR, the 230-bp band and the 330-bp band were amplified from sample 3 and 4, respectively. The results from the two rhPCR strategies were in agreement with one another and with the RFLP analysis. Without RNase H2, no PCR product was amplified in any rhPCR reaction (data not shown). All reactions with $2 \mathrm{mU}$ RNase $\mathrm{H} 2$ per primer pair produced identical results (data not shown) as the reactions with $1 \mathrm{mU}$ RNase H2. This indicated that rhPCR technique was as accurate as the RFLP technique for the purpose of identification of $P$. australis subspecies. The result also suggested that $1 \mathrm{mU}$ RNase $\mathrm{H} 2$ per primer pair in $20-\mu \mathrm{L}$ reactions is a sufficient enzyme concentration. Given the fact the duplex rhPCR was more efficient (simpler and less time consuming), but equally accurate compared with either RFLP or the single rhPCR, this technique was used in all future analyses.

\section{Invasive subspecies predominates over the natives in Alberta}

In total 28 samples were received by APHL in 2016 and 2017. Among these samples, 27 were visually identified as $P$. australis and one as a sedge species (Carex species). The 27 putative $P$. australis samples were derived from 21 colonies in nine counties across Alberta (Fig. 3). RFLP and duplex rhPCR analyses generated identical results on the subspecies identities of these 27 samples. Among the 27 P. australis, 19 were identified as invasive and 8 were native subspecies. Samples from the same colonies submitted by different people or in different years were 
confirmed to be the same subspecies, including three invasive samples from Greenview and Newell, respectively, two invasive samples from Strathcona and two native samples from Lac La Biche. Thus, in total 14 colonies were identified as invasive and seven colonies were native subspecies across the province (Fig. 3). Both analyses did not amplify PCR product from the sedge sample (data not shown).

\section{Discussion}

The RFLP technique has been extensively used for subspecies identification in the APHL and elsewhere (Saltonstall 2003a; Larson et al. 2011; Allen et al. 2017). In this study we developed a duplex rhPCR protocol, which is as accurate as the RFLP method but less time consuming. For one sample, at least eight hours were needed for RFLP analysis, whereas only three hours were required to obtain the duplex rhPCR results. The efficiency of rhPCR became more prominent when multiple samples were being tested. In addition, the duplex rhPCR is less expensive than RFLP. For 100 samples, the cost of primers and restriction enzymes for the RFLP method is more than $\$ 100$ but the cost of rhPCR primers and RNase H2 is less than $\$ 3$. Thus we recommend the duplex rhPCR for future subspecies identification efforts of $P$. australis subspecies.

During the development of the rhPCR protocol, three RNase H2 concentrations were tested. No PCR products were produced using blocked primers in the absence of RNase $\mathrm{H} 2$, indicating that the rhPCR primers were inactive and did not spontaneously cleave to give rise to an active amplification under PCR conditions. rhPCR with $1 \mathrm{mU}$ or $2 \mathrm{mU}$ RNase per primer pair per 20$\mu \mathrm{L}$ reaction generated identical results, indicating that $1 \mathrm{mU}$ RNase $\mathrm{H} 2$ per primer pair per 20$\mu \mathrm{L}$ reaction was sufficient for the analysis. It is worth noting that the concentration of RNase $\mathrm{H} 2$ 
required for a successful analysis is influenced by other PCR conditions, especially the annealing and elongation times (Dobosy et al. 2011). According to the principle of rhPCR (Dobosy et al. 2011), RNase H2 cleavage is highly specific to the ribonucleotide when it matches the nucleotide on the template. However, the enzyme may also have slight cleavage activity on mismatched ribonucleotides. For this reason, one might expect to see two duplex PCR bands from one sample if excessive RNase $\mathrm{H} 2$ was used. In this study, using the recommended protocol with $1 \mathrm{mU}$ enzyme per primer pair in $20-\mu \mathrm{L}$ reactions, no sample produced double bands. Therefore, we recommend the rhPCR protocol with $1 \mathrm{mU}$ RNase $\mathrm{H} 2$ per primer pair in $20-\mu \mathrm{L}$ reactions.

Chloroplast DNA is maternally inherited and thus potential native/invasive hybrid populations cannot be identified with rhPCR. However, the existence of such populations is unlikely (Saltonstall 2003b). In addition, the rhPCR cannot specifically identify the actual haplotypes. Furthermore, the duplex rhPCR would not generate a band from certain plants such as those of haplotype I as described in Saltonstall (2003a). The absence of band from duplex rhPCR may require a re-run of the rhPCR or other techniques such as DNA sequencing. Nevertheless, the duplex rhPCR will greatly assist in genotype-specific management of $P$. australis populations and help to identify and target control efforts on invasive populations.

In this study a small number of $P$. australis samples were tested, from which a clear conclusion on the subspecies distribution could not be drawn. Based on the tested samples, we found that the invasive subspecies was more common in Alberta than the native subspecies. This is in contrast with the recent finding in British Columbia where only 9 out of 203 specimens were found to be the invasive subspecies of $P$. australis (Allen et al. 2017). After its initial introduction along the Atlantic coast, the invasive subspecies has gradually expanded westward 
over many decades (Saltonstall 2002). Catling and Mitrow (2011) predicted that the invasive subspecies would eventually become abundant across the continent. Data from this study, along with the data from Allen et al. (2017) suggested that the invasive subspecies is already prevalent in Alberta and poised to spread to British Columbia.

A number of pathways have facilitated P. australis spread throughout North America, but the most predominant are transportation routes, including roads, railways, or shipping routes which create pathways between habitat ideal for colonization (Brisson et al. 2010). Many of the invasive subspecies samples included in this study were collected along the roadsides of highways. Whether this possibly indicates the potential of highways as an invasion pathway in Alberta is unknown because roadside colonies are also more conspicuous and easier to access for sample collection. Future study in Alberta will include a provincial survey with larger sample sizes and a wider geographical range. This will help clarify the subspecies distribution and the major invasion pathway(s) of the P. australis subspecies australis across Alberta.

\section{Acknowledgements}

We would like to thank Quentin Bochar, Catherine Christensen, Hazel Edwards, Todd Green, Dennis Haglund, Jenifer Hammel and Keisha Hollman for collecting P. australis samples from the field. This work was supported by the Alberta Crop Industry Development Fund [grant number 2012C015D].

\section{References}

Allen, G.A., McCormick, L.J., Jantzen, J.R., Marr, K.L., and Brown, B.N. 2017. Distributional and morphological differences between native and introduced common reed (Phragmites 
australis, Poaceae) in Western Canada. Wetlands, 37(5): 819-827. doi:10.1007/s13157-0170914-4.

Brisson, J., de Blois, S., and Lavoie, C. 2010. Roadside as invasion pathway for common reed (Phragmites australis). Invasive Plant Sci. Manage. 3(4): 506-514. doi:10.1614/IPSM-09050.1 .

Catling, P.M., and Mitrow, G. 2011. The recent spread and potential distribution of Phragmites australis subsp. australis in Canada. Can. Field-Nat. 125(2): 95-104. doi:10.22621/cfn.v125i2.1187.

Chambers, R., Meyerson, L., and Saltonstall, K. 1999. Expansion of Phragmites australis into tidal wetlands of North America. Aquat. Bot. 64(3): 261-273. doi:10.1016/S03043770(99)00055-8.

Dobosy, J.R., Rose, S.D., Beltz, K.R., Rupp, S.M., Powers, K.M., Behlke, M.A., and Walder, J.A. 2011. RNase H-dependent PCR (rhPCR): improved specificity and single nucleotide polymorphism detection using blocked cleavable primers. BMC Biotechnol. 11: 80. doi:10.1186/1472-6750-11-80. PMID:21831278.

Integrated DNA Technologies. 2017. Application guide for rhPCR experiments. Available from http://www.idtdna.com/pages/docs/default-source/user-guides-and-protocols/rnaseh-deppcr_application-guide_v4.pdf.

Larson, D.L., Galatowitsch, S.M., and Larson, J.L. 2011. Native and European haplotypes of Phragmites australis (common reed) in the central Platte River, Nebraska. Great Plains Res. 21(2): 175-180.

Mal, T.K., and Narine, L. 2004. The biology of Canadian weeds. 129. Phragmites australis (Cav.) Trin. ex Steud. Can. J. Plant Sci. 84(1): 365-396. doi:10.4141/P01-172. 
Orson, R.A. 1999. A paleoecological assessment of Phragmites australis in New England tidal marshes: changes in plant community structure during the last few millennia. Biol. Invasions, 1(2): 149-158. doi:10.1023/A:1010047731369.

Saltonstall K., Lambert, A., and Meyerson, L.A. 2010. Genetics and reproduction of common (Phragmites australis) and giant reed (Arundo donax). Invasive Plant Sci. Manage. 3(4): 495505. doi:10.1614/IPSM-09-053.1.

Saltonstall, K. 2002. Cryptic invasion by a non-native genotype of the common reed, Phragmites australis, into North America. Proc. Natl. Acad. Sci. U.S.A. 99(4): 2445-2449. doi:10.1073/pnas.032477999. PMID:11854535.

Saltonstall, K. 2003a. A rapid method for identifying the origin of North American Phragmites populations using RFLP analysis. Wetlands, 23(4): 1043-1047. doi:10.1672/02775212(2003)023[1043:ARMFIT]2.0.CO;2.

Saltonstall, K. 2003b. Microsatellite variation within and among North American lineages of Phragmites australis. Mol. Ecol. 12(7): 1689-1702. doi:10.1046/j.1365-294X.2003.01849.x.

Saltonstall, K., Peterson, P.M., and Soreng, R.J. 2004. Recognition of Phragmites australis subsp. americanus (Poaceae: Arundinoideae) in North America: evidence from morphological and genetic analyses. SIDA, Contrib. Bot. 28(2): 683-692. 
Table 1. Oligonucleotide primers used in this study.

\begin{tabular}{lll}
\hline Name & Sequence (5'-3') & Origin \\
\hline$t r n L b R$ & GGAGAAGATAGAATCATAGC & Saltonstall 2002 \\
$t r n \mathrm{~L}$ & TCTACCGATTTCGCCATATC & Saltonstall 2002 \\
$\operatorname{trnL-F}$ & TAAGGAGAAGATAGAATCATAGC & This study \\
$\operatorname{trnL-R}$ & TGAAACCAGGATTCCTTGTGTArCTTGTC/3SpC3/ & This study \\
$r b c L$ & TGTACAAGCTCGTAACGAAGG & Saltonstall 2003a \\
$r b c L 3 R$ & GATTTGTCAAGTCTCATGATCGT & Saltonstall 2003a \\
rbcL-F & AGGCGATCAAATTCGAGTTCGrCGCCGC/3SpC3/ & This study \\
rbcL-R & GATTTGTCAAGTCTCATGATCG & This study
\end{tabular}




\section{Figure legends}

Fig. 1. Chloroplast DNA sequence polymorphism on the $\operatorname{trn} \mathrm{T}-\operatorname{trn} \mathrm{L}(\mathrm{A})$ and $r b c \mathrm{~L}-p s a l$ (B) regions between native and invasive subspecies of Phragmites australis. These polymorphisms were the theoretical basis of RFLP and rhPCR. Inv and Nat refer to DNA sequences of chloroplast from an Invasive (GenBank accession no: KF730315) and a Native (KJ825856) plant, respectively. In the RFLP analysis, PCR product amplified by the primer pair $\operatorname{trn} \mathrm{LbR} / \operatorname{trnL}$ was digested with $R s a \mathrm{I}(\mathrm{A})$, and PCR product amplified by $r b c \mathrm{~L} / r b c \mathrm{~L} 3 \mathrm{R}$ was digested with $H h a \mathrm{I}(\mathrm{B})$. In the rhPCR, primer pairs trnL-F/trnL-R and rbcL-F/rbcL-R were used in alternative (single) or the same (duplex) reactions.

Fig. 2. Identification of Phragmites australis subspecies by RFLP and rhPCR analyses. A, Expected size (base pairs) of visible bands from native and invasive subspecies produced by RFLP or rhPCR. B, RFLP analysis of five $P$. australis samples. C, rhPCR analysis of two $P$. australis samples. 1-5, P. australis samples derived from different counties of Alberta; a and c, PCR products by primer pairs $\operatorname{trn} \mathrm{LbR} / \operatorname{trn} \mathrm{L}$ and $r b c \mathrm{~L} / r b c \mathrm{~L} 3 \mathrm{R}$, respectively; $\mathrm{b}, R s a \mathrm{I}$ digest of a; $\mathrm{d}$, HhaI digest of c; e and f, rhPCR products of primer pairs trnL-F/trnL-R and rbcL-F/rbcL-R, respectively; $M$ and M', Promega 100-bp (M) and 1-kb (M') DNA ladders.

Fig. 3. Distribution of native and invasive subspecies of Phragmites australis in nine counties in Alberta. The number of colonies from each county is indicated on the map. 


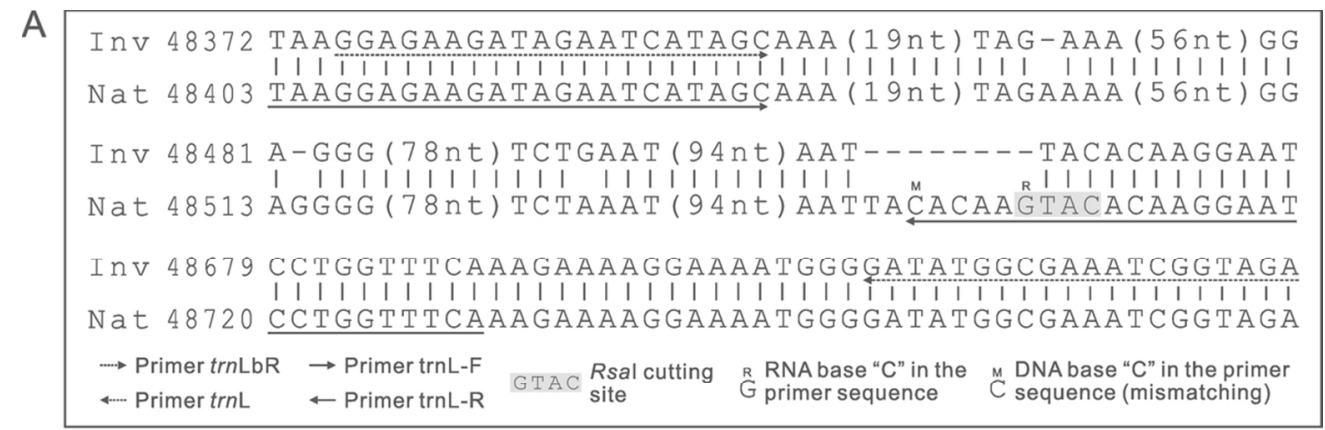

B

Inv 57830 TGTACAAGCTCGTAAGAAGGGCGGATCTTGCTCGTG (60nt) AAA Nat 57846 TGTACA I I I I I I I I I I I I I I I I I I I I I I I I I I I I I I I I I I I I I I I I I I I I

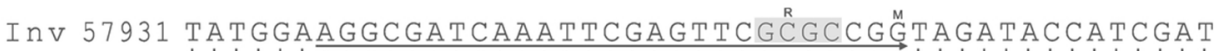

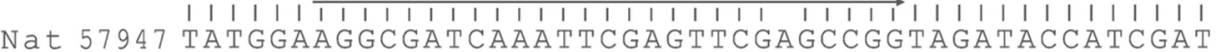
Inv 57978 TAAGTAG (152nt) AGATCTTGATACGACATGAGACTTGACAAATC

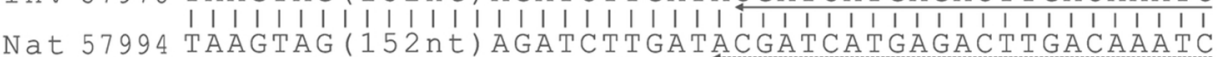

$\rightarrow$ Primer $r b c L \quad \rightarrow$ Primer rbcL-F $\quad$ Hhal cutting $R$ RNA base "C" in the $M$ DNA base "C" in the primer $\leftarrow$ Primer $r b c L 3 R \leftarrow$ Primer rbcL-R $G C G C$ site $\quad{ }_{C}^{R}$ primer sequence ${ }_{G}^{M}$ sequence (mismatching)

\section{$99 \times 66 \mathrm{~mm}(300 \times 300 \mathrm{DPI})$}




\begin{tabular}{|lccccccc|}
\hline $\mathrm{A}$ & \multicolumn{2}{c}{$\mathrm{RFLP}$} & & \multicolumn{2}{c|}{ Single rhPCR } & Duplex \\
\cline { 2 - 3 } & \multicolumn{2}{c}{$\operatorname{trnL}$} & $\mathrm{rbcL}$ & & trnL & rbcL & rhPCR \\
\hline Native & 300,60 & 320 & & 330 & no band & 330 \\
Invasive & 350 & 200,100 & & no band & 230 & 230 \\
\hline
\end{tabular}
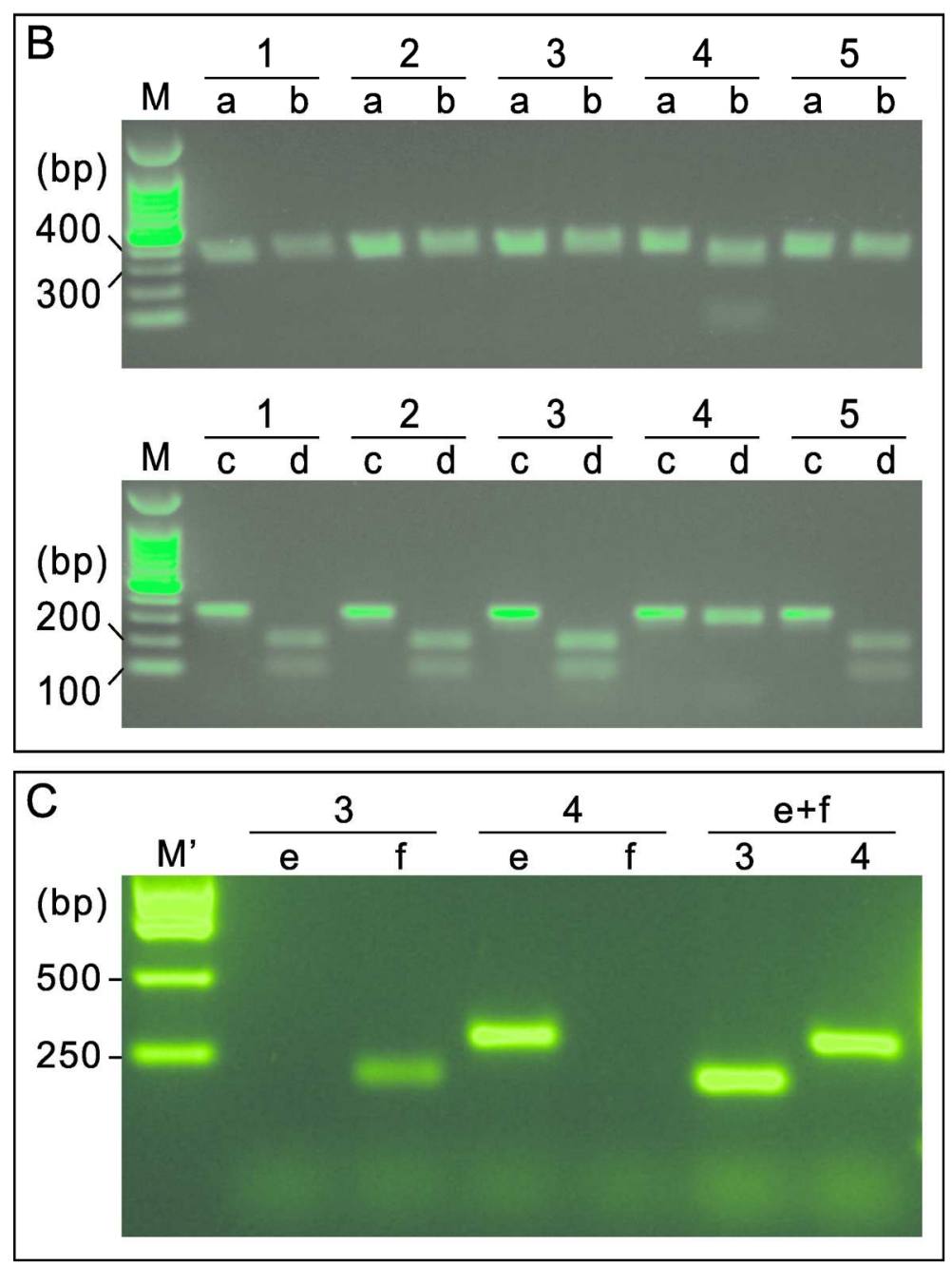

$136 \times 218 \mathrm{~mm}(300 \times 300 \mathrm{DPI})$ 


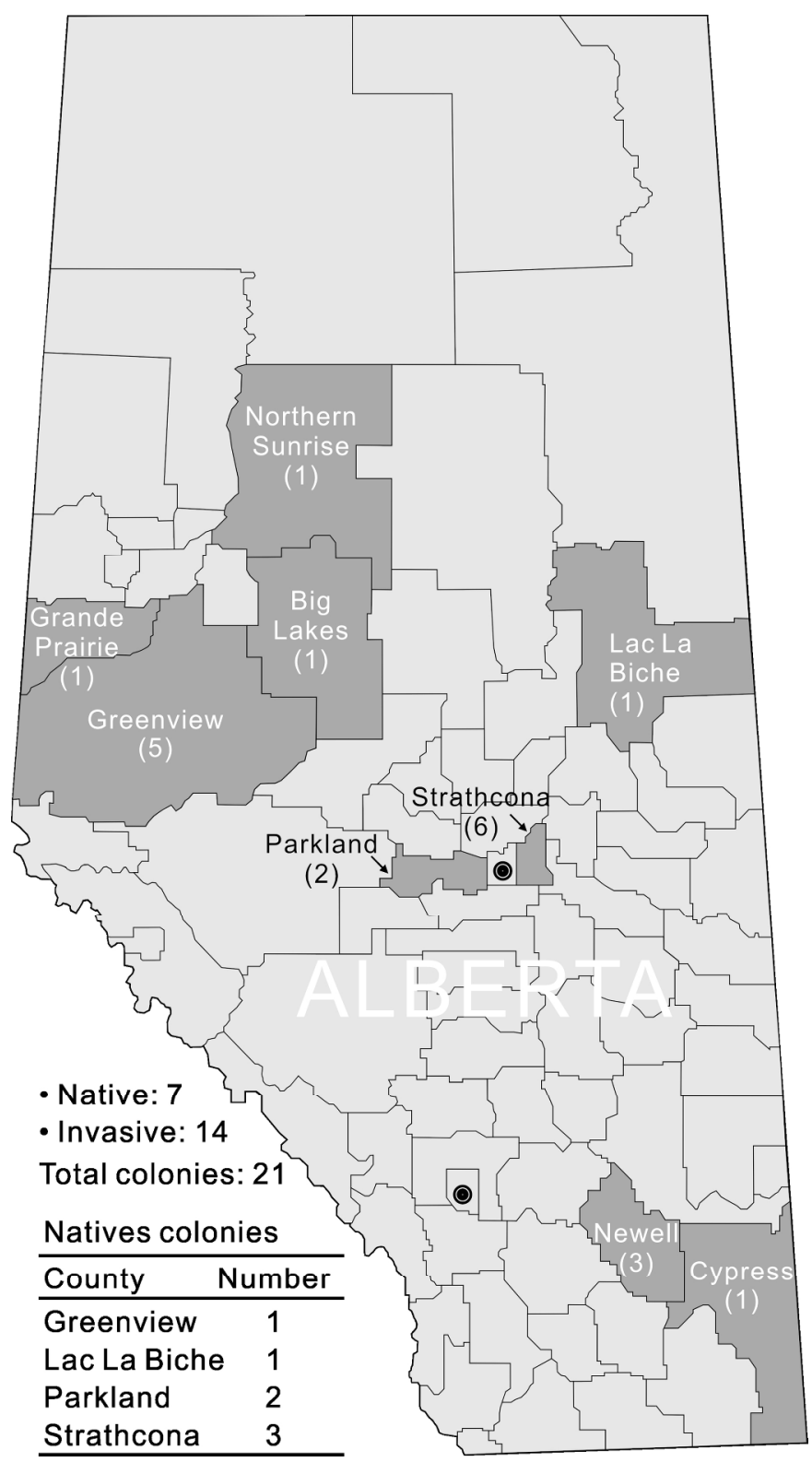

$154 \times 279 \mathrm{~mm}(300 \times 300 \mathrm{DPI})$ 